\title{
MULTIMODE SCANNING NEAR-FIELD PHOTOLUMINESCENCE SPECTROSCOPY AND ITS APPLICATION FOR STUDIES OF InGaN EPITAXIAL LAYERS AND QUANTUM WELLS
}

\author{
S. Marcinkevičius, T.K. Uždavinys, R. Ivanov, and M. Mensi \\ KTH Royal Institute of Technology, Department of Applied Physics, Electrum 229, 16440 Kista, Sweden \\ Email: sm@kth.se
}

Received 1 February 2018; accepted 22 March 2018

\begin{abstract}
The paper reviews our recent achievements in developing a multimode scanning near-field optical microscopy (SNOM) technique. The multimode SNOM apparatus allows us to simultaneously measure spatial variations of photoluminescence spectra in the illumination and illumination-collection modes, their transients and sample surface morphology. The potential of this technique has been demonstrated on a polar InGaN epitaxial layer and nonpolar InGaN/GaN quantum wells. SNOM measurements have allowed revealing a number of phenomena, such as the band potential fluctuations and their correlation to the surface morphology, spatial nonuniformity of the radiative and nonradiative lifetimes, as well as the extended band nature of localized states. The combination of different modes enabled measurements of the ambipolar carrier diffusion and its anisotropy.
\end{abstract}

Keywords: near-field, SNOM, photoluminescence, InGaN, diffusion, recombination

PACS: 07.79.Fc, 78.55.Cr, 78.47.jd

\section{Introduction}

Photoluminescence (PL) spectroscopy is one of the most popular experimental methods for studies of optical properties, band structure, and defects in semiconductors [1, 2]. Typically, it is performed by focusing excitation onto a sample with a lens or a microscope objective. For such far-field excitation, the smallest excitation spot diameter and the spatial resolution of the measurement are restricted by the diffraction limit to about a wavelength. Oil immersion objectives and confocal microscopy allow increasing the spatial resolution by a factor of two, but the resolution limit is still defined by the wavelength. To detach the spatial resolution from the wavelength constraints, a conceptually new approach is needed. One of such approaches is to use non-propagating near-field radiation, which can be confined to a volume with dimensions much smaller than the wavelength.
Combined with the scanning probe microscopy concept, the scanning near-field PL spectroscopy offers a high resolution, non-destructive and versatile method for material characterization [3].

In the scanning near-field optical microscopy (SNOM or NSOM), the near-field radiation is usually produced by launching laser light into a thinned, metal coated fibre probe with a typical aperture of $\sim 100-150 \mathrm{~nm}$ (apertures as small as $20 \mathrm{~nm}$ have been reported [件). Replacing the fibre probe with a sharp probe without an aperture, manufactured from, e.g. metal, Si, diamond or C nanotube [5], allows increasing the spatial resolution to about $10 \mathrm{~nm}$. However, the apertureless SNOM is mostly used for measurements of light scattering because methods of spectral measurements are not yet developed to the full extent.

The SNOM technique is by no means limited to studies of PL or electroluminescence. Measurements of light transmission, reflection and scattering 
allow studying a wide spectrum of material properties, such as electronic, vibrational, magnetic and optical, including studies of band structure, electron and phonon transport, and defects [3]. Compared to cathodoluminescence, a popular technique for high-resolution measurements of light emission, the positive distinction of SNOM is that it permits wavelength selective excitation allowing to address particular regions of a heterostructure and a simultaneous mapping of the optical properties and surface morphology.

In the field of semiconductors, SNOM is particularly useful for studies of alloys, in which even slight alloy composition fluctuations may cause considerable band potential variations and affect the optical and transport properties. Here GaN-based ternary nitrides, $\mathrm{Al}_{x} \mathrm{Ga}_{1-x} \mathrm{~N}, \mathrm{In}_{x} \mathrm{Ga}_{1-x} \mathrm{~N}$ and $\operatorname{In}_{x} \mathrm{Al}_{1-x} \mathrm{~N}$, stand out. Since the band gaps of the binary constituents differ by several eV (6.2 eV for AlN, $3.6 \mathrm{eV}$ for $\mathrm{GaN}$ and $0.7 \mathrm{eV}$ for $\mathrm{InN}$ ), even minuscule spatial composition variations induce such effects as the spectral broadening [ [ 6 , spatial nonuniformity of radiative and nonradiative recombination times [7], and increased alloy scattering [8]. All of these phenomena have a large impact of the efficiency and longevity of GaN-based photonic and electronic devices.

Typically, near-field PL measurements are performed by applying excitation through the probe and collecting the PL signal either through the same probe (illumination-collection, or ICmode) or in the far field (illumination, or I-mode), often through a transparent substrate. In most cases, a single probe is used. Dual probe technique has been developed and applied for studies of ambipolar carrier diffusion [9]; however, for ternary nitrides, in which diffusion lengths are of the order of $100 \mathrm{~nm}$, such experiments are complicated due to mechanical difficulties and the near-field crosstalk between the closely located probes. As will be shown below, the transport parameters can be assessed from single probe measurements as well. In that case, though, a multimode SNOM operation is required.

In this paper, we review our recent achievements in development of the multimode single probe SNOM and demonstrate how measurements of PL and surface morphology parameters provide rich information on the electronic, transport and material growth properties of InGaN epitaxial layers and quantum wells (QWs).

\section{Experiment}

The experimental set-up for the scanning multimode near-field PL spectroscopy is shown in Fig. 1. It is based on a commercial scanning near-field

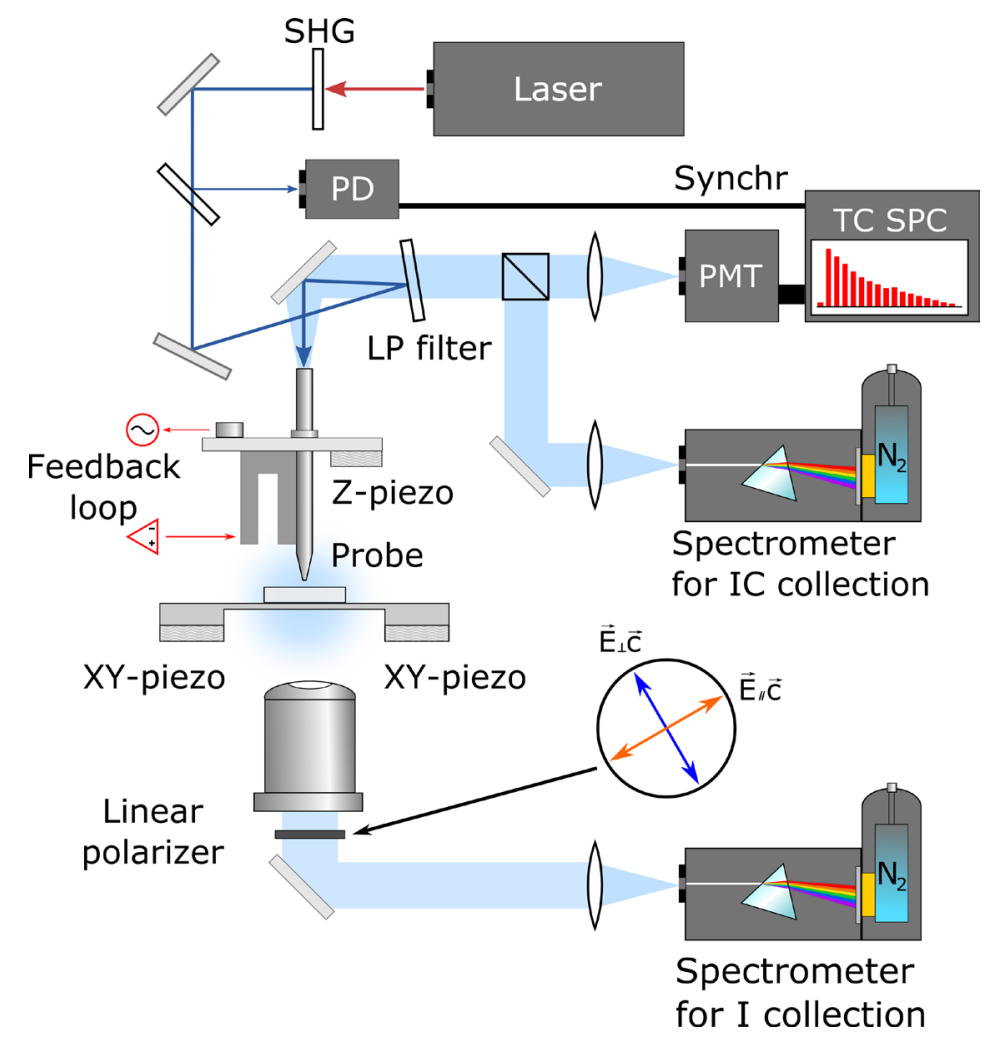

Fig. 1. Experimental setup. Reproduced with permission from [39]. Copyright (2017) American Chemical Society. 
optical microscope Multiview 4000 from Nanonics Imaging, Ltd. In all experimental configurations, the sample was excited through the probe. PL was collected either through the probe, or simultaneously through the probe and a high numerical aperture (0.45) microscope objective located on the substrate side of the sample (the I-mode). To analyse PL polarization, a linear sheet analyser was inserted after the objective. The probes were manufactured from a multimode UV fibre by chemical etching $(50 \% \mathrm{HF})$ and coating with a thin aluminium layer. Typical probe aperture diameters were 100 to $150 \mathrm{~nm}$. The probe was glued to a quartz tuning fork and a constant probe-sample distance was maintained using a shear-force feedback. The feedback signal was used to map morphology of the sample surface. A typical scan area varied between $5 \times 5$ and $20 \times 20 \mu \mathrm{m}^{2}$, with a step size between 50 and $200 \mathrm{~nm}$, respectively.

PL was excited with 2 nd harmonic pulses from a Ti:sapphire laser with a pulse duration of $150 \mathrm{fs}$, a pulse repetition rate of $80 \mathrm{MHz}$ and a central wavelength between 320 and $400 \mathrm{~nm}$. PL spectra in the I- and IC-modes were measured with two spectrometers equipped with liquid $\mathrm{N}_{2}$ cooled CCD detectors. For spectrally- and time-resolved measurements, the IC-mode PL beam was split by a beam splitter, and the corresponding beams directed into the spectrometer and a time-correlated single photon counter (TCSPC). The spectral resolution of the measurements was $0.5 \mathrm{~nm}$ and the temporal response of the TCSPC system was 50 ps. The spectrometers and the TCSPC were synchronized with a SNOM pixel clock; thus, the near-field PL spectra in the I- and IC-modes, the near-field PL transients in the IC-mode, and the surface morphology were measured simultaneously at each pixel of a scan.

The studied samples were grown on low dislocation density $\left(\sim 10^{6} \mathrm{~cm}^{-2}\right)$ GaN substrates by metalorganic chemical vapour deposition. The $100 \mathrm{~nm}$ thick epitaxial $c$-plane $\operatorname{In}_{0.09} \mathrm{Ga}_{0.91} \mathrm{~N}$ layer on a GaN template was grown at École Polytechnique Fédérale de Lausanne (EPFL). The substrate was miscut at 0.3 to $0.5^{\circ}$ angle towards the $[10 \overline{1} 0]$ direction. The QW structures were produced at the University of California, Santa Barbara (UCSB). They were grown on an $m$-plane substrate followed by a 1-2 $\mu \mathrm{m}$ thick Si-doped or undoped $\mathrm{GaN}$ buffer. The QW thickness was 8 to
$10 \mathrm{~nm}$ and the In content was between 15 and $18 \%$. The $m$-plane substrates were either nominally on-axis or miscut at $1^{\circ}$ angle towards the [0001] direction. To enable SNOM measurements in the I-mode, the substrate side of some samples was polished by chemical-mechanical polishing. The InGaN layers and QWs were fully strained, as confirmed by X-ray measurements.

\section{Results and discussion}

In the following, we illustrate how different modes of the scanning near-field PL spectroscopy contribute to understanding of the material growth, spatial variation of the alloy composition, properties of light emission and carrier transport.

\subsection{Spectrally-resolved SNOM applied on InGaN epitaxial layers}

The band potential fluctuations in InGaN QWs may be induced by variations of the alloy composition, QW width and strain [10, 11]. To separate the composition effect from those of the QW width, epitaxial layers were studied.

The band gap variations of the ternary nitrides can be subdivided into those of a large and a small scale providing a dual localization [12, 13. The large-scale (hundreds of nm to a few $\mu \mathrm{m}$ ) fluctuations can be traced via spatial variations of the PL peak energy. The small-scale fluctuations, occurring within several to tens of nm [14], i.e. in areas much smaller than the SNOM probe aperture, can be evaluated indirectly via the linewidth of the emission spectrum [13]. The latter is determined by the homogeneous broadening defined by carrier interaction with phonons and the inhomogeneous broadening induced by band potential fluctuations.

In partially relaxed layers, the InGaN alloy composition has been found to be nonuniform in the growth direction because of the varying strain [15]. The alloy composition may also experience lateral variations due to the presence of extended defects that induce the lateral strain variation $[16,40]$. Moreover, there have been suggestions that variations of the alloy composition may also be linked to the surface morphology, as shown for InGaN QWs [18-20]. Using SNOM, we investigate this effect in the InGaN layer. 
Figure 2 displays maps of the surface morphology, its gradient in the horizontal direction, and PL peak energy. The morphology map and large area scans [21] indicate that the surface is covered by large undulations that are parallel to the miscut direction and laterally spread over tens to hundreds of $\mu \mathrm{m}$. The undulations are observed on samples with and without the InGaN layer, i.e. they originate from the $\mathrm{GaN}$ template. They emerge during the step-flow growth due to step meandering that occurs because of the EhrlichSchwöbel barrier for adatom movement down the monolayer steps [21].

By inspecting the maps of Fig. 2, one can notice a strong correlation between the maps of the morphology gradient and the peak PL energy. The correlation graph for these parameters is presented in Fig. 3. The absolute value of the Pearson product-moment coefficient for this correlation is large, $r=-0.63$. Since the peak energy is directly (a) morphology $(\mathrm{nm})$

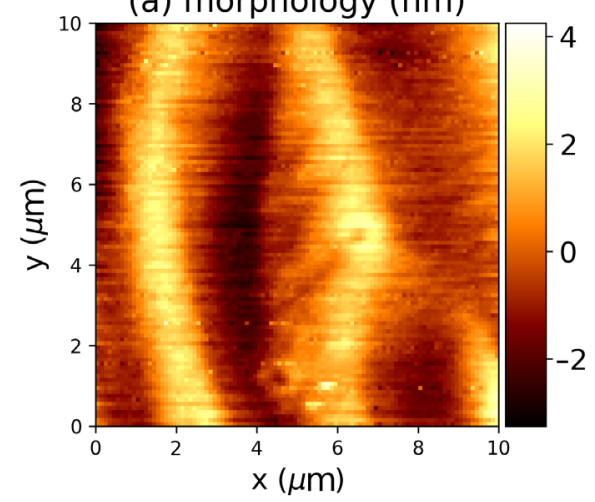

(c) peak energy (eV)

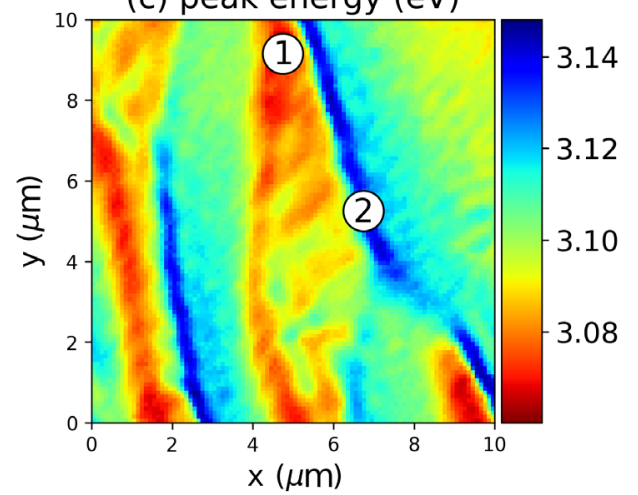

(b) $\nabla_{x}$ morphology

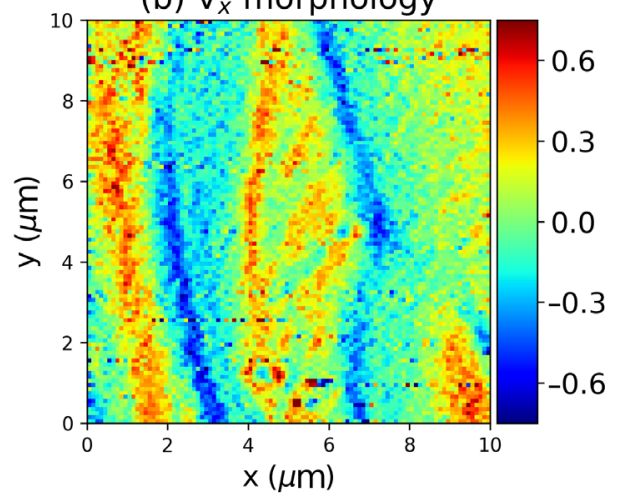

(d) NF spectra

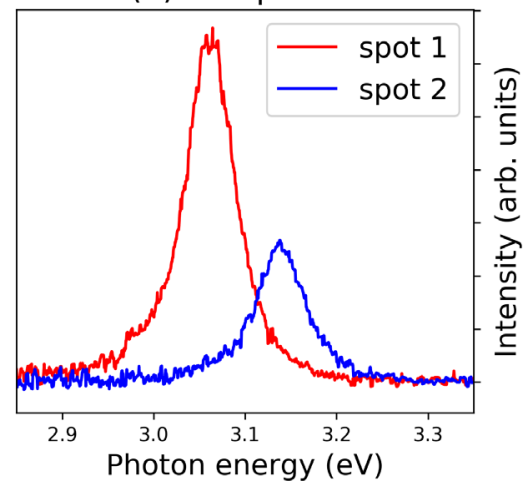

Fig. 2. Maps of the surface morphology (a), its gradient along the $x$ axis (b) and PL peak energy (c). Part (d) displays the spectra recorded at points indicated on the map (c).

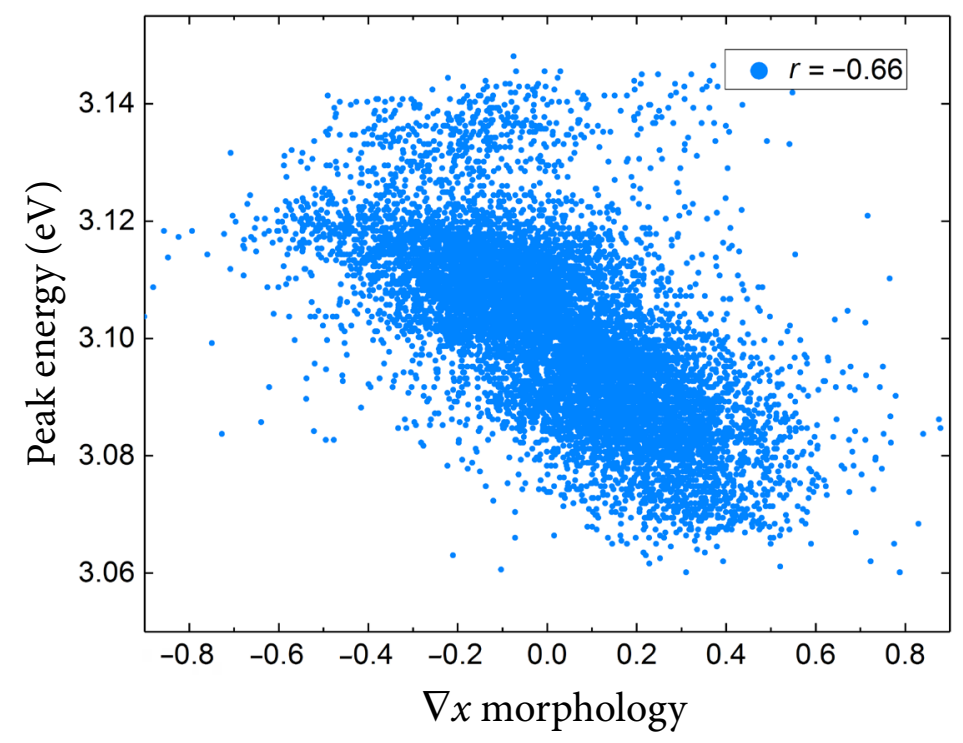

Fig. 3. Correlation of the PL peak energy with the morphology gradient in the direction perpendicular to the $\mathrm{GaN}$ template meanders. 
related to the alloy composition, the correlation shows that different slopes of the meanders have a different In content. The average peak energy for the different $\mathrm{GaN}$ meander slopes differs by as much as $80 \mathrm{meV}$, which corresponds to the In content variation of 0.02 , or $\sim 25 \%$ of the average In percentage. This is also reflected in the PL spectra from the different slopes, shown in Fig. 2(d).

The difference of In content on the different slopes of undulations can be related to the surface morphology. A high resolution atom force microscopy (AFM) map [22] is presented in Fig. 4. The map shows that the surface is covered with steps that are characteristic of the step-flow growth mode [21]. GaN and InGaN are grown in nitrogen-rich conditions; hence, velocity of the step growth is determined by the cation incorporation rate. This rate is different for plane edges with a different number of dangling nitrogen bonds that can be either one or two [23]. The crucial feature of the steps shown in Fig. 4 is that on one side of the meander (slope 1) the steps are aligned along the crystallographic axis ([11ㅣㅇㅣ for the miscut direction perpendicular to the nonpolar (10 $\overline{1} 0)$ plane), while on the other side (slope 2) they are not. This means that on slope 2 step edges have a zigzag shape (with typical dimensions of $\sim 10 \mathrm{~nm}$; hence, not resolved in Fig. 4). Consequently, in slope 1 step edges mostly contain nitrogen atoms with two dangling bonds, while on slope $1 \mathrm{~N}$ atoms with single and double bonds are

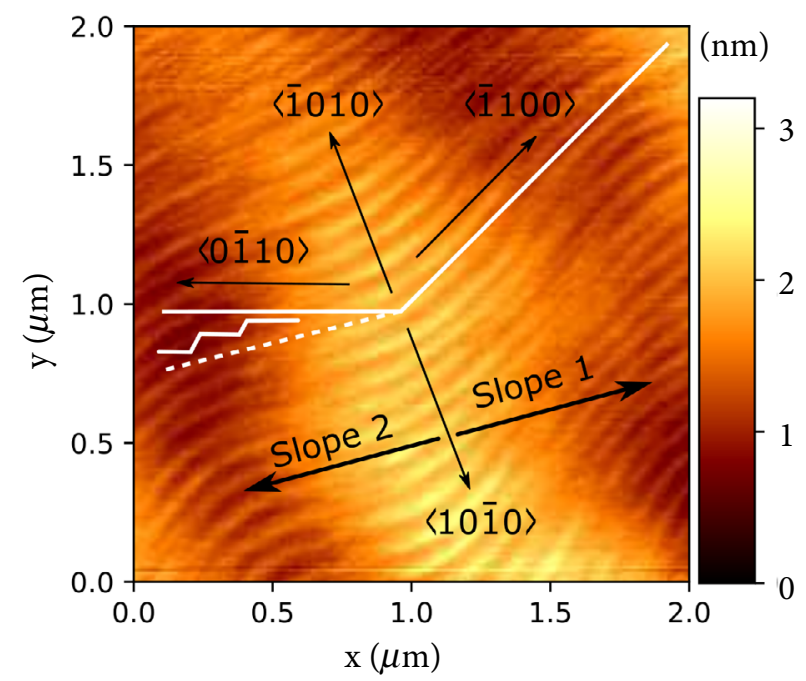

Fig. 4. High resolution AFM scan of a meander region showing the divergence of growth steps from the crystallographic axis on slope 2. present. This must have an effect on the indium incorporation because In atoms are preferentially adsorbed at sites with a smaller number of dangling $\mathrm{N}$ bonds (an energetically more favourable configuration [24]). Consequently, the In content on slope 2 would be higher, just as observed in the experiment.

\subsection{Time-resolved SNOM}

Below we demonstrate how the time-resolved SNOM allows mapping parameters of PL dynamics as well as of radiative and nonradiative recombination times. The experiments are performed on nonpolar $m$-plane In GaN/GaN quantum wells that are promising for LED and laser applications.

Commercial GaN-based laser and light emitting diodes are based on $c$-plane InGaN QWs with the growth direction parallel to the polar $\mathbf{c}$ axis. However, such QWs have a serious drawback, namely, large, $\sim 1 \mathrm{MeV} / \mathrm{cm}$ transverse electric field caused by the difference of the spontaneous and piezoelectric polarizations of well and barrier materials. The field separates electrons and holes located in the QW and decreases the rate of their radiative recombination. This makes the recombination more susceptible to nonradiative processes reducing the internal quantum efficiency. Hence, at the expense of an increased carrier density and a potentially increased Auger recombination, narrow, $~ 2-3 \mathrm{~nm}$ thick QWs must be used. To avoid these drawbacks, nonpolar QWs with the c axis lying in the QW plane were proposed [25]. Indeed, in such QWs, even as wide as $10 \mathrm{~nm}$, the radiative lifetimes are short, of the order of 1 ns [26]. Yet, the ideal picture of an $m$-plane QW, used in device simulations, does not take into account the band potential fluctuations and in-plane electric fields originating from the non-planarity of QW interfaces [27, 28]. These nanoscopic fields might localize electrons and holes at separate sites affecting the wave function overlap and the radiative recombination time.

Figure 5 presents a few PL transients and spectra measured at different points of a scan. As can be noticed, the transients and spectra experience considerable spatial variations. Measuring PL transients at each point of the scan allows plotting maps of the PL decay time $\tau_{\mathrm{PL}}$ (evaluated from a single-exponential fit) and the transient 


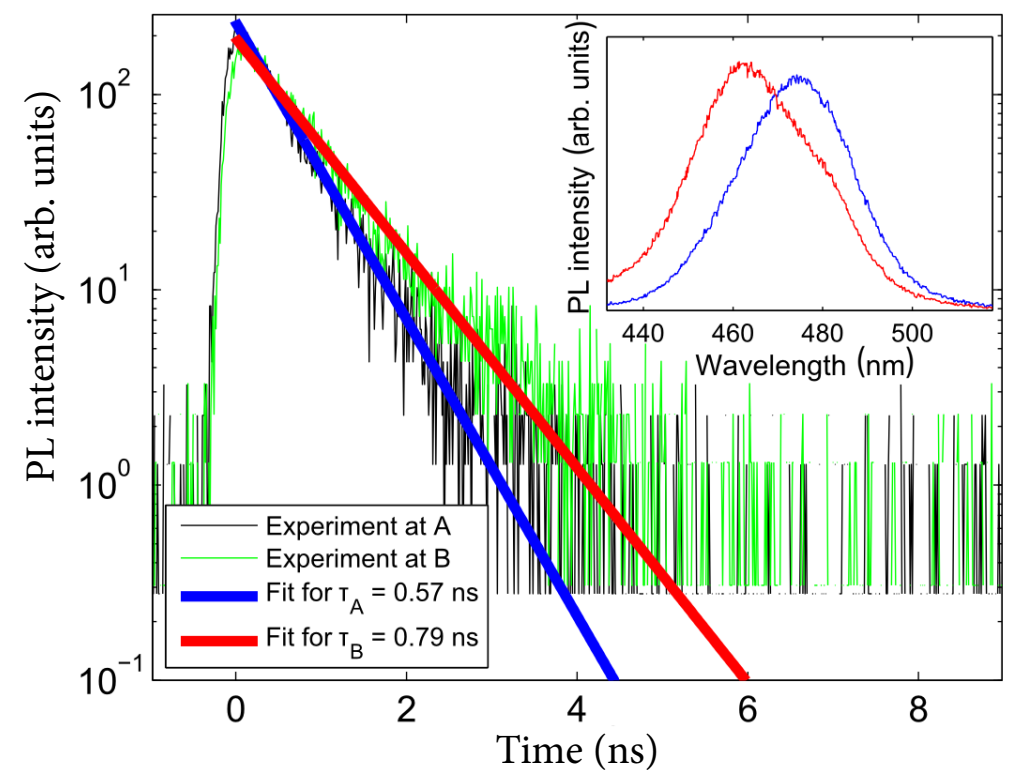

Fig. 5. $300 \mathrm{~K}$ near-field PL transients and spectra at selected points of a scan. Reproduced with permission from [7]. Copyright (2017) American Institute of Physics. amplitude $I_{\max }$. These maps were subsequently used to calculate maps of the radiative $\tau_{\mathrm{R}}$ and nonradiative $\tau_{\mathrm{NR}}$ lifetimes [林. For that purpose, an average room temperature radiative lifetime was evaluated from far-field time-resolved PL measurements performed with a streak camera for temperatures between 4 and $300 \mathrm{~K}$. In the evaluation, the peak of the PL transient was considered inversely proportional to $\tau_{\mathrm{R}}[26,29]$, and the recombination at $4 \mathrm{~K}$ and early times after the excitation was assumed to be purely radiative. Such a procedure provided the average radiative recombination time of 1.9 ns. It served to normalize the radiative lifetime map that was calculated from the inverted transient amplitude map using the relation $1 / \tau_{\mathrm{R}} \propto I_{\max }$ 26]. The nonradiative lifetime values for each point of the scan were calculated from the maps of the radiative and PL lifetimes following $1 / \tau_{\mathrm{NR}}=1 / \tau_{\mathrm{PL}}-1 / \tau_{\mathrm{R}}$.

The maps of the recombination times are presented in Fig. 6. The figure also shows maps of the morphology gradient and integrated PL intensity. One can notice that both, the radiative and nonradiative lifetimes are position dependent. The spatial radiative lifetime variations originate from varying electron and hole wave function overlap. In InGaN QWs, localization of holes is much stronger than that of electrons because of the larger effective mass [29], and electron localization at room temperature is often ignored. Our data explicitly demonstrate that this assumption is not correct.
The largest deviation of the radiative lifetimes from the average value occurs at steep hillock facets with a negative slope towards the $+\mathbf{c}$ axis. The increased radiative lifetime signals that in these regions the average electron and hole wave function overlap is smaller, and, consequently, the electron localization is stronger. The increased spatial separation of electrons and holes on the steepest $+c$ slopes may occur due to locally rougher QW interfaces. Nonuniform interfaces induce in-plane electric fields that may separate photoexcited electrons and holes resulting in their localization at different potential minima [27, 28.

The spatial variation of $\tau_{\mathrm{NR}}$ signals that spatial distribution of the nonradiative recombination centres is nonuniform. The nonradiative lifetime map has a significant anticorrelation with the map of the peak wavelength $(r=-0.41)$ []. Since the regions with a longer peak wavelength have a higher average In content, the correlation shows that an increase of the In content is accompanied by a higher concentration of the nonradiative recombination centres, presumably point defects.

Apart from the $+c$ slopes of the on-axis QW, correlations of $\tau_{\mathrm{R}}$ and $\tau_{\mathrm{NR}}$ with the morphology and its gradient are small. This demonstrates that other morphology features (hillock planes, striations) have little effect on the electron localization and the spatial distribution of the impurities and point defects in $m$-plane QWs. 

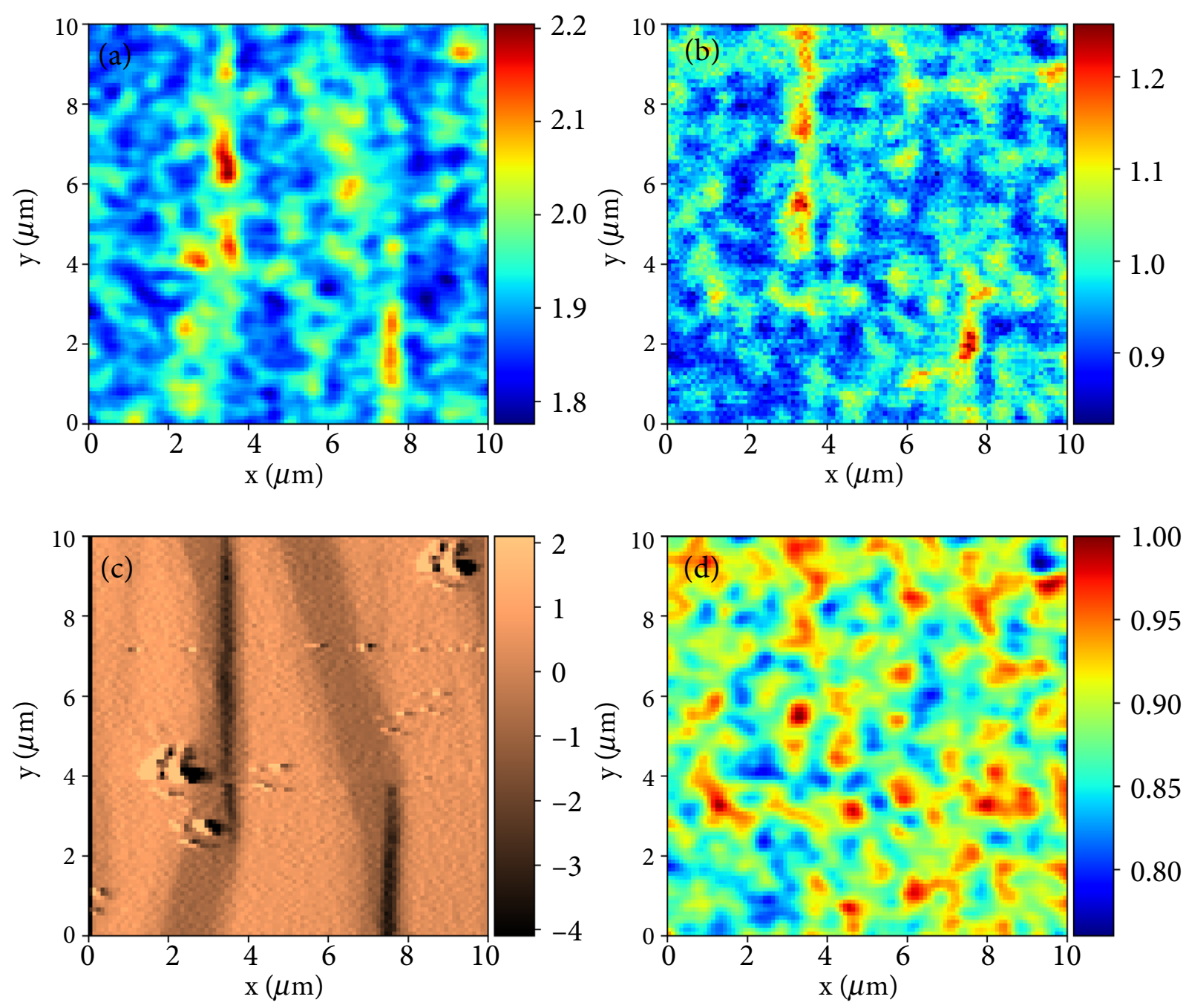

Fig. 6. SNOM maps of radiative (a) and nonradiative (b) lifetimes, topography gradient along the $\mathbf{c}$ axis (c) and integrated PL intensity (d) for the $m$-plane InGaN QW. Reproduced with permission from [7]. Copyright (2017) American Institute of Physics.

\subsection{Polarization-resolved SNOM for studies of localized states in m-plane In GaN quantum wells}

Another near-field PL parameter that, so far, has been largely overlooked, is the polarization. Below we show an example how analysis of the spatial distribution of the emitted polarization allows assessing properties of localized states and defects. It also provides information on the band structure of bulk materials and QWs [20].

In polar $c$-plane InGaN layers and QWs, the emitted PL is unpolarized. For nonpolar and semipolar crystallographic configurations, PL is elliptically polarized. A common parameter to analyse this polarization is the degree of linear polarization, defined as $D L P=\left(I_{\perp}-I_{\|}\right) /\left(I_{\perp}+I_{\|}\right)$, where $I_{\perp}$ and $I_{\|}$are PL intensities for polarizations perpendicular and parallel to the projection of the $\mathbf{c}$ axis to the layer plane. The polarization of the optical transitions originates from the anisotropy of strain in an InGaN layer grown on the lattice mismatched GaN [31]. Predominant polarization for the transition to the uppermost valence band is $\mathbf{E} \perp \mathbf{c}$ and to the second band $\mathbf{E}|| \mathbf{c}$. The splitting between the two topmost hole bands increases with strain; thus, increasing the InN molar fraction in an $m$-plane InGaN layer results in a larger valence band separation. Quantum confinement modifies the valence band states, however, the two uppermost levels originate from the first and second bands in the bulk material maintaining the selection rules. The DLP is related to the thermal 
energy $k T$ and the intervalence band energy $\Delta E$ via the equation [20]

$$
D L P=(1-\beta \exp (-\Delta E /(k T))) /(1+\beta \exp (-\Delta E /(k T))),
$$

where $\beta$ is a composite parameter that depends on the ratio between the matrix elements of the considered interband transitions and the ratio between the joint densities of states of the corresponding band levels.

In $m$-plane InGaN QWs, the band potential variations are large, and recombination predominantly takes place from the localized states. This is evidenced by the large shift of $230 \mathrm{meV}$ for the $\mathbf{E} \perp \mathbf{c}$ PL peak for temperatures between 4 and $300 \mathrm{~K}$ [20], which is much larger than the shift of the GaN band gap (70 meV [31]). This difference indicates that the shift of the QW peak is primarily determined by the carrier redistribution between the localized states rather than by the band gap shrinkage.

The origin of the localized states, e.g. random alloy composition fluctuations, cation clustering, local strain relaxation at extended defects, etc., should have an imprint on the emitted light polarization. Consequently, by studying spatial variations of the PL polarization with a high spatial resolu- tion, information on the properties of the localized states could be obtained. Moreover, since localization and defects may depend on the surface morphology [19], SNOM measurements of the spatial variations of light emission and the morphology could explicitly reveal relations between growth and the origin of the localized states.

When measuring PL polarization with SNOM, one should bear in mind that the IC-mode is not an appropriate experimental configuration. This is because the near-field of radiation contains both transverse and longitudinal components [32], and PL polarization collected through a fibre probe cannot be analysed in terms of the polarization of a plane wave. However, the PL polarization can be assessed using a different experimental configuration, namely, the I-mode, in which PL is a propagating radiation in the far-field. In the experiment, the DLP map was calculated from spectrally integrated PL intensity maps measured in subsequent scans for perpendicular analyser positions. Small variations of the scanned area were corrected by comparing surface morphology maps recorded simultaneously with the PL measurements.

Figure 7 displays the maps of the surface morphology, the PL peak wavelength for $\mathbf{E} \perp \mathbf{c}$
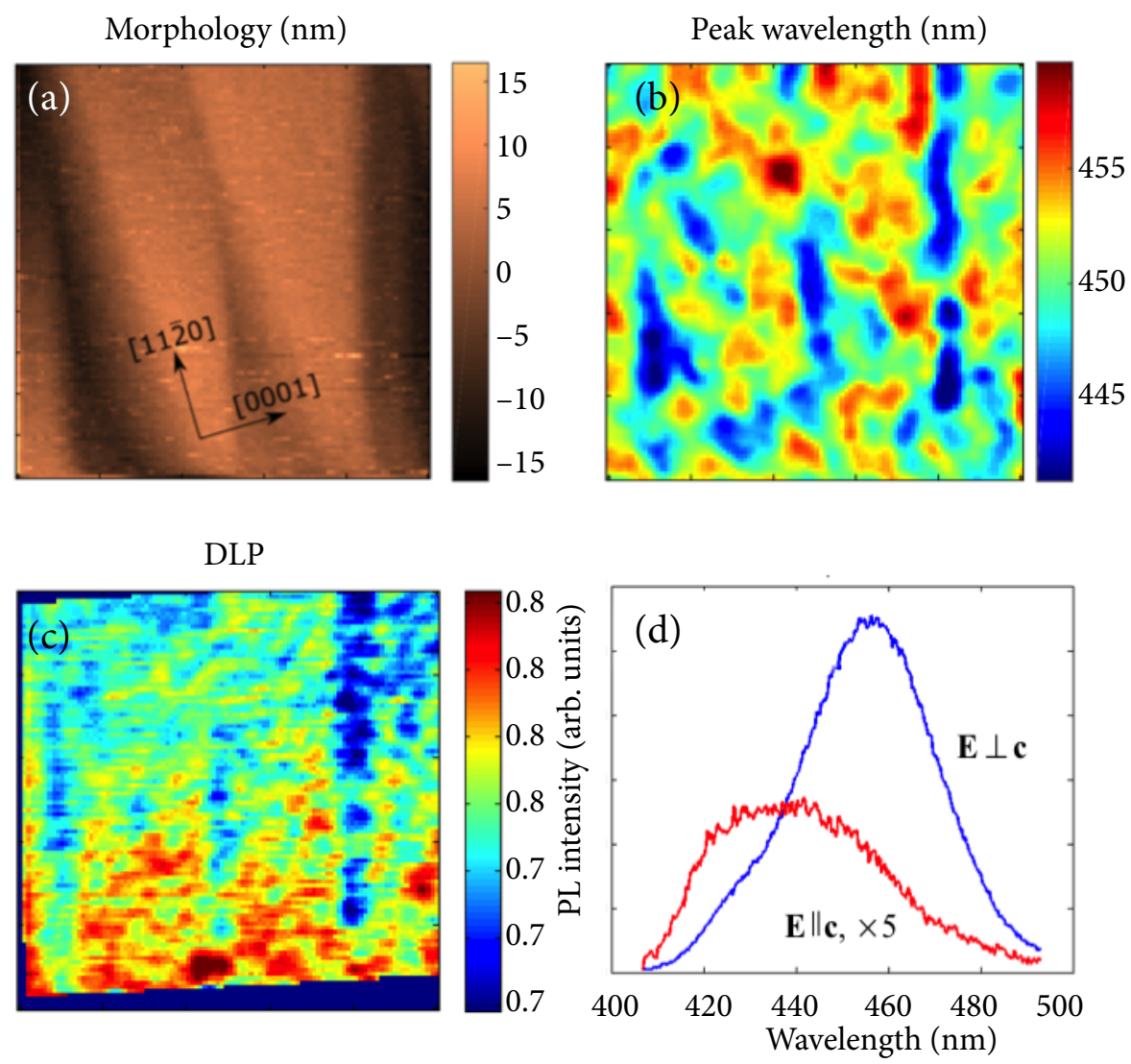

Fig. 7. $10 \times 10 \mu \mathrm{m}^{2}$ maps of surface morphology (a), peak wavelength (b), DLP (c) and selected spectra for PL polarization perpendicular and parallel to the $\mathbf{c}$ axis (d). Reproduced with permission from Ref. 20. Copyright (2017) American Physical Society. 
polarization, the DLP and typical near-field spectra for both polarizations. The blue shift of the E || $\mathbf{c}$ spectrum with respect to the $\mathbf{E} \perp \mathbf{c}$ spectrum reflects the prevailing transitions to the first and second valence band levels, respectively. As the conduction band has the s-type symmetry, the DLP is determined by the properties of the valence band.

As can be seen from Fig. Z (c), the DLP is large despite that PL is emitted from the deep localized states. This explicitly shows that the localized states are not caused by states of a different symmetry such as defects, In-rich quantum dot like formations or inclusions of a semipolar phase [29, 33, 34, but have the same properties as the corresponding bands.

More insight into the DLP of transitions related to deep and shallow localized states can be obtained by subdividing the broad PL band into three Gaussian components. Constraints applied in the deconvolution were the following: a) peak energies and linewidths for the constituent peaks were the same for $\mathbf{E} \perp \mathbf{c}$ and $\mathbf{E} \| \mathbf{c}$ spectra measured at a particular point of a scan; b) the peak energy of an $\mathbf{E} \perp \mathbf{c}$ spectrum was set as the peak energy of the middle peak; c) the peak energy of high energy peak was chosen as the peak energy of the $\mathbf{E} \| \mathbf{c}$ spectrum. The peak energy of the long wavelength peak, reflecting contribution of the deep localized states, was obtained from the best fit. The linewidth and intensity values of the constituent peaks were allowed to vary as free parameters.

Let us discuss the DLP maps related to the middle and the long wavelength components. The latter is related to the deep localized states. The DLP of the main peak has a little spatial variation with an average value of 0.94 and a standard deviation of 0.02 . The division of the near-field PL peaks into the three components largely eliminates the contribution of transitions to the 2 nd valence band level, and the main peak DLP reflects properties of the ground state transitions. The largest DLP value is as high as 0.98 , showing that the transition is fully polarized, as suggested by the calculations for ideal bands without the band potential fluctuations [34]. The main peak DLP is close to the largest values measured for nonpolar and semipolar InGaN QWs [29, 33-35] at low temperatures, at which thermal population of the 2 nd valence band level is negligible.

For the long wavelength peak, the average DLP is smaller and the standard deviation is larger $(0.7$ and 0.2 , respectively). In some spots the DLP is close to zero, as pointed by white arrows on the map of Fig. 8(d). Clearly, the symmetry properties of these
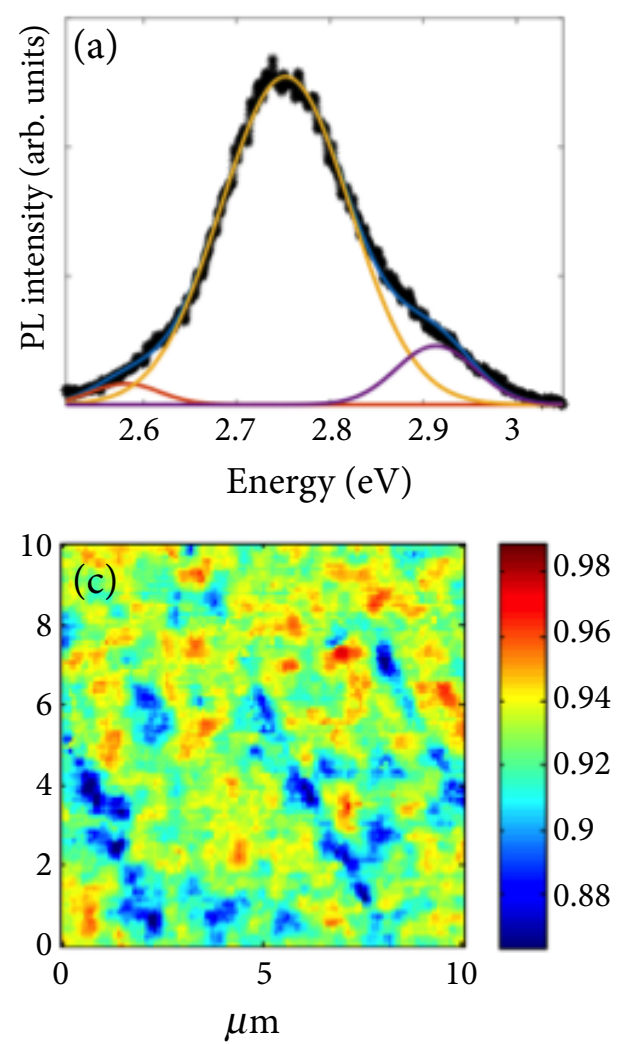
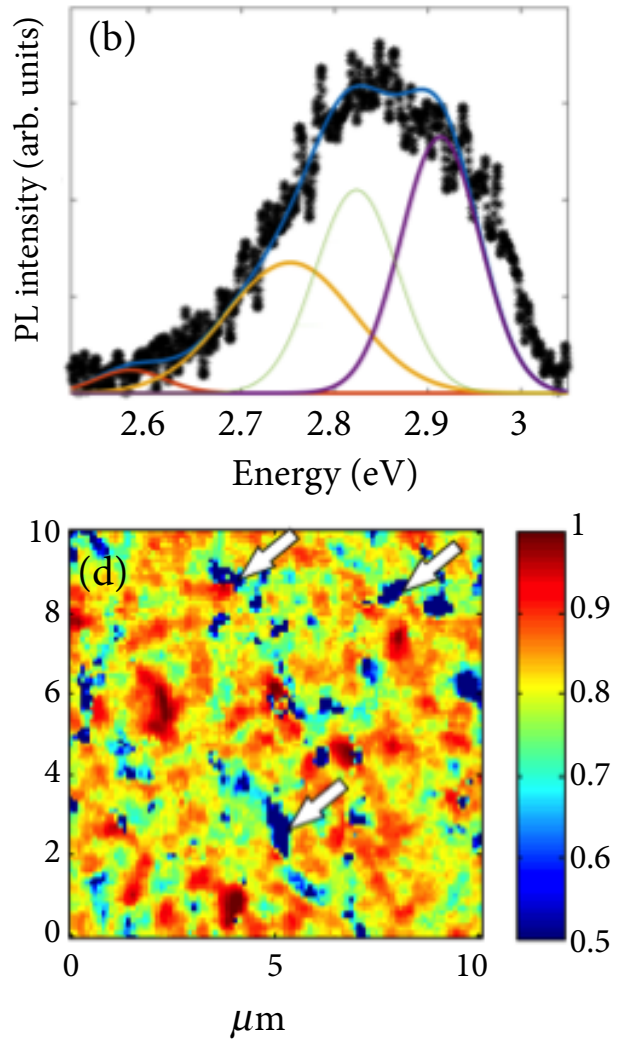

Fig. 8. Deconvolution of the PL spectra for $E \perp c$ (a) and $E \| c$ (b) polarizations, and DLP maps for the main (c) and low energy (long wavelength) peak (d). Reproduced with permission from [20]. Copyright (2017) American Physical Society. 
states are different from those of the ideal bands. Our near-field data suggest that these regions might be related to the strain relaxation around dislocations because the DLP is much lower than expected for the semipolar phase inclusions [35, 36. Besides, in these areas the peak wavelength is longer, as should be expected for the strain-relaxed regions. One should note, however, that these spots are observed only for the long wavelength PL component, which accounts for just a few percent of the overall PL, and do not have low DLP analogues in the main peak map.

\subsection{Combined multimode SNOM for optical measurements of carrier diffusion}

Lateral equilibration of the injected carrier concentration in QWs that form an active region of a light emitting or laser diode is a process critical for an efficient operation and long lifetime of these devices. Here, because of the large hole effective mass, the hole diffusion is the limiting factor. An efficient hole diffusion is especially critical for the ternary nitride QW devices because it is strongly affected by the large band potential fluctuations and hole localization.

Typically, diffusion parameters are evaluated from electrical mobility measurements in $p$-type materials. For III-nitrides, because of the high binding energy and the low activation level of $\mathrm{Mg}$ acceptors, heavy doping is required. The doping increases concentration of defects and ionized impurity scattering, which results in lower mobility values as compared to intrinsic or lightly doped materials. An alternative approach is to use contactless methods that rely on an optical detection of carrier motion. A popular technique to evaluate diffusion length is to measure an increase of the luminescing area with respect to the excitation spot [37]. However, this method is limited to materials with large diffusion lengths. For a diffusion length of the order of $100 \mathrm{~nm}$, the luminescing spot is barely larger than the excited area. Diffusion measurements using a transient grating require high power pulses and, therefore, may be affected by heating effects [38]. Moreover, the grating method has a limited spatial resolution as well. Compared to the mentioned techniques, SNOM stands out because it allows a small excitation spot far beyond the diffraction limit. A two- probe experiment, in which one stationary fibre probe is used for an optical carrier injection and another one scans the sample collecting PL emitted by the diffused carriers, is the most straightforward approach [9]. However, for small, sub- $\mu \mathrm{m}$ diffusion lengths, this technique becomes very complicated because of the mechanical difficulties in positioning the probes close to each other and the near-field interaction between them.

Below we describe a single probe based SNOM technique that allows measuring diffusion parameters and their anisotropy using multimode SNOM operation [39]. Scanning over small, $\mu \mathrm{m}$ size areas the technique allows measuring local diffusion parameters. The method is demonstrated for a nonpolar $m$-plane InGaN/GaN quantum well.

The method is based on the comparison of PL intensity maps measured in the IC- and I-modes. The difference between these modes is that in the IC-mode recorded PL is generated only by carriers that, during their lifetime, remain under the probe. For the I-mode, all the photogenerated carriers contribute to the measured signal. As a result, the PL intensity measured at a point in the ICmode is affected by the radiative and nonradiative recombination times at the measurement point and the diffusion. For the I-mode, parameters that determine the PL intensity are the recombination times at the measurement point and its surroundings.

To evaluate the diffusion parameters, we developed the following method. First, PL intensity maps in the IC- and I-modes as well as PL transients, providing amplitude and decay time maps were measured. The latter were used to build maps of the radiative and nonradiative recombination times, as described in Subsection 3.2. Then, the maps of $\tau_{\mathrm{R}}$ and $\tau_{\mathrm{NR}}$ were used as a basis to simulate PL intensity maps in I- and IC-modes using an iteration procedure described in [39]. In the simulation, the independent components of the diffusion tensor parallel and perpendicular to the $\mathbf{c}$ axis were treated as adjustable parameters. To simplify the calculations, the carrier recombination and diffusion were treated as separate processes alternating in small time steps. The calculated diffusion coefficient values are achieved by minimizing the difference between the calculated and measured PL maps. As can be seen from Fig. 9 , 

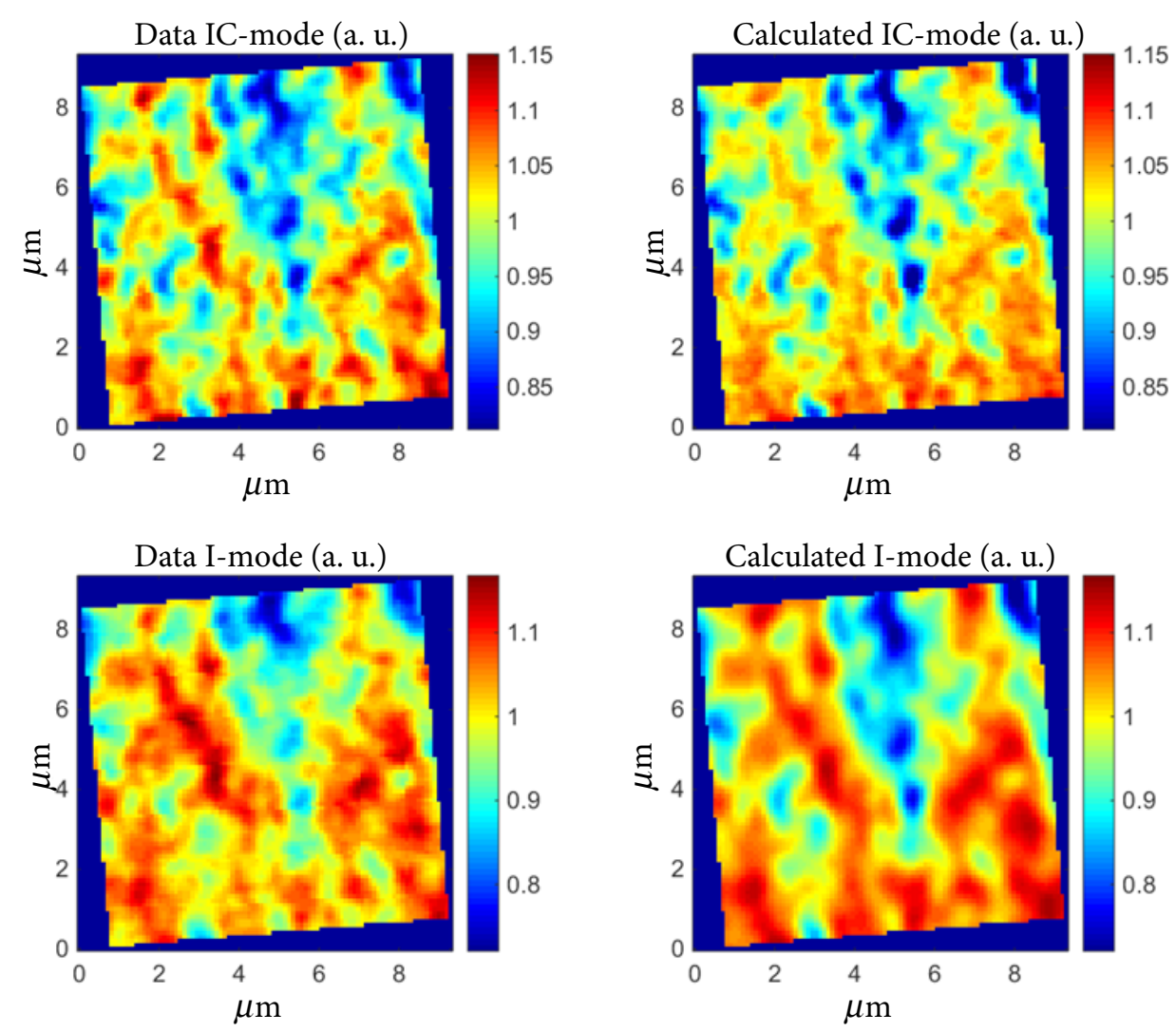

Fig. 9. Measured (left column) and calculated (right column) PL intensity maps for IC- (top row) and I-mode (bottom row). Reproduced with permission from [39]. Copyright (2017) American Chemical Society.

the match between the measured and the calculated PL intensity maps is excellent. The high repeatability of the results achieved in subsequent runs supports reliability of the method.

The calculated ambipolar diffusion coefficient components are $D_{\| \mathrm{c}}=0.4 \mathrm{~cm}^{2} / \mathrm{s}$ and $D_{\perp c}=1.9 \mathrm{~cm}^{2} / \mathrm{s}$. The ambipolar process is governed by the slower holes with $D_{\mathrm{amb}} \approx 2 D_{\mathrm{h}}$. The ambipolar diffusion in the $m$-plane InGaN QW is anisotropic and almost 5 times faster along the [1120] (a) direction than along the [0001] (c) direction. Since the hole diffusion coefficient is inversely proportional to the hole effective mass, the measured diffusion anisotropy suggests that the hole effective mass is highly anisotropic. Indeed, the $\mathbf{k} \cdot \mathbf{p}$ band structure calculations for $m$-plane InGaN layers and QWs show that two top-most valence bands experience a strong dispersion anisotropy near the centre of the Brillouin zone [36, 40]. The calculated effective mass in the ground valence band level for the bulk $m$-plane $\mathrm{In}_{0.15} \mathrm{Ga}_{0.85} \mathrm{~N}$ and the $3 \mathrm{~m}$ $\mathrm{In}_{0.15} \mathrm{Ga}_{0.85} \mathrm{~N} / \mathrm{GaN} \mathrm{QW}$ is about 5 times smaller in the a direction. For the QW, the numerical values are $0.38 m_{0}$ and $1.91 m_{0}$, respectively [40]. Diffusion anisotropy, obtained in our experiments, is in excellent agreement with the calculated anisotropy of the effective mass.

\section{Conclusions}

A multimode scanning near-field microscopy technique has been described and its potential demonstrated on the InGaN epitaxial layer and InGaN/GaN QWs. Different SNOM modes have allowed revealing a number of phenomena, such as the band potential fluctuations and their correlation with the surface morphology, the spatial nonuniformity of the radiative and nonradiative lifetimes, as well as the extended band nature of the localized states. Combination of the different SNOM modes enabled measurements of the short distance ambipolar carrier diffusion and its anisotropy. All these examples demonstrate SNOM as a versatile technique allowing one to access a multitude of material parameters and study their spatial distribution with a high spatial resolution.

\section{Acknowledgements}

We would like to thank James S. Speck, Leah Y. Kuritzky, Kathryn M. Kelchner, Steven P. DenBaars and Shuji Nakamura from UCSB for the growth and structural characterisation of the nonpolar QW samples, and the discussion on properties of these quantum wells. Nicolas Grandjean, 
Raphaël Butté, Lise Lahourcade, Jean-François Carlin and Denis Martin from EPFL are acknowledged for the InGaN epilayer sample, AFM and $\mathrm{X}$-ray measurements, and discussions of the peculiarities of the step-flow growth and properties of InGaN. The work has been performed within the frame of Linnaeus Advanced Centre of Optics and Photonics and supported by the Swedish Energy Agency (Contract No. 45390-1) and the Swedish Research Council.

\section{References}

[1] J. Jimenez and J.T. Tomm, Spectroscopic Analysis of Optoelectronic Semiconductors (Springer, Berlin, 2016).

[2] I. Pelant and J. Valenta, Luminescence Spectroscopy of Semiconductors (Oxford Scholarship Online, Oxford, 2012).

[3] E. Betzig and J.K. Trautman, Near-field optics: microscopy, spectroscopy and surface modification beyond the diffraction limit, Science 257(5067), 189-195 (1992).

[4] K. Matsuda, T. Saiki, S. Nomura, M. Mihara, Y. Aoyagi, S. Nair, and T. Takagahara, Nearfield optical mapping of exciton wave functions in a GaAs quantum dot, Phys. Rev. Lett. 91(17), 177401 (2003).

[5] S. Patané, P.G. Gucciardi, M. Labardi, and M. Allegrini, Apertureless near-field optical microscopy, Riv. Nuovo Cimento 27(1), 1 (2003).

[6] G. Steude, B.K. Meyer, A. Göldner, A. Hoffmann, F. Bertram, J. Christen, H. Amano, and I. Akasaki, Optical investigations of AlGaN on GaN epitaxial films, Appl. Phys. Lett. 74(17), 2456 (1999).

[7] R. Ivanov, S. Marcinkevičius, T.K. Uždavinys, L.Y. Kuritzky, S. Nakamura, and J.S. Speck, Scanning near-field microscopy of carrier lifetimes in $m$-plane InGaN quantum wells, Appl. Phys. Lett. 110, 031109 (2017).

[8] A. Teke, S. Gökden, R. Tülek, J.H. Leach, Q. Fan, J. Xie, Ü. Özgür, H. Morkoç, S.B. Lisesivdin, and E. Özbay, The effect of AlN interlayer thicknesses on scattering processes in lattice-matched AlInN/ GaN two-dimensional electron gas heterostructures, New J. Phys. 11, 063031 (2009).
[9] A. Kaneta, R. Fujimoto, T. Hashimoto, K. Nishimura, M. Funato, and Y. Kawakami, Instrumentation for dual-probe scanning near-field optical microscopy, Rev. Sci. Instrum. 83, 083709 (2012).

[10]D. Watson-Parris, M.J. Godfrey, P. Dawson, R.A. Oliver, M.J. Galtrey, M.J. Kappers, and C.J. Humphreys, Carrier localization mechanisms in $\operatorname{In}_{x} \mathrm{Ga}_{1-x} \mathrm{~N} / \mathrm{GaN}$ quantum wells, Phys. Rev. B 83, 115321 (2011).

[11]T.K. Uždavinys, D.L. Becerra, R. Ivanov, S. Nakamura, S.P. DenBaars, J.S. Speck, and S. Marcinkevičius, Influence of well width fluctuations on recombination properties in semipolar InGaN quantum wells studied by time- and spatially-resolved near-field photoluminescence, Opt. Mater. Express 7(9), 3116-3123 (2017).

[12]K. Kazlauskas, G. Tamulaitis, P. Pobedinskas, A. Žukauskas, M. Springis, C.F. Huang, Y.C. Cheng, and C.C. Yang, Exciton hopping in $\mathrm{In}_{x} \mathrm{Ga}_{1-x} \mathrm{~N}$ multiple quantum wells, Phys. Rev. B 71, 085306 (2005).

[13]V. Liuolia, S. Marcinkevičius, Y.D. Lin, H. Ohta, S.P. DenBaars, and S. Nakamura, Carrier localization in $m$-plane InGaN/GaN quantum wells probed by scanning near field optical spectroscopy, Appl. Phys. Lett. 97, 151106 (2010).

[14]T.-J. Yang, R. Shivaraman, J.S. Speck, and Y.-R. Wu, The influence of random indium alloy fluctuations in indium gallium nitride quantum wells on the device behavior, J. Appl. Phys. 116, 113104 (2014).

[15]S. Pereira, M.R. Correia, E. Pereira, K.P. O'Donnell, C. Trager-Cowan, F. Sweeney, and E. Alves, Compositional pulling effects in $\operatorname{In}_{x} \mathrm{Ga}_{1-x} \mathrm{~N} / \mathrm{GaN}$ layers: A combined depth-resolved cathodoluminescence and Rutherford backscattering/channeling study, Phys. Rev. B 64, 205311 (2001).

[16]A. Mouti, J.-L. Rouvière, M. Cantoni, J.-F. Carlin, E. Feltin, N. Grandjean, and P. Stadelmann, Stress-modulated composition in the vicinity of dislocations in nearly lattice matched $\mathrm{Al}_{x} \mathrm{In}_{1-x} \mathrm{~N} /$ $\mathrm{GaN}$ heterostructures: A possible explanation of defect insensitivity, Phys. Rev. B 83, 195309 (2011). 
[17]S. Marcinkevičius, Y. Zhao, K.M. Kelchner, S. Nakamura, S.P. DenBaars, and J.S. Speck, Nearfield investigation of spatial variations of $(20 \overline{2} \overline{1})$ InGaN quantum well emission spectra, Appl. Phys. Lett. 103, 131116 (2013).

[18]T. Lermer, I. Pietzonka, A. Avramescu, G. Brüderl, J. Müller, S. Lutgen, and U. Strauss, Interdependency of surface morphology and wavelength fluctuations of indium-rich InGaN/GaN quantum wells, Phys. Status Solidi A 208(5), 1199-1202 (2011).

[19]K.M. Kelchner, L.Y. Kuritzky, K. Fujito, S. Nakamura, S.P. DenBaars, and J.S. Speck, Emission characteristics of single InGaN quantum wells on misoriented nonpolar $m$-plane bulk GaN substrates, J. Cryst. Growth 382, 80-86 (2013).

[20]R. Ivanov, S. Marcinkevičius, M. Mensi, O. Martinez, L.Y. Kuritzky, D.J. Myers, S. Nakamura, and J.S. Speck, Polarization resolved near-field spectroscopy of localized states in nonpolar InGaN/ GaN quantum wells, Phys. Rev. Appl. 7, 064033 (2017).

[21]N.A.K. Kaufmann, L. Lahourcade, B. Hourahine, D. Martin, and N. Grandjean, Critical impact of Ehrlich-Schwöbel barrier on GaN surface morphology during homoepitaxial growth, J. Cryst. Growth 433, 36-42 (2016).

[22]T.K. Uždavinys, S. Marcinkevičius, M. Mensi, L. Lahourcade, J.-F. Carlin, D. Martin, R. Butté, and N. Grandjean, Impact of surface morphology on properties of light emission in InGaN epilayers, Appl. Phys. Express [submitted].

[23]M.H. Xie, S.M. Seutter, W.K. Zhu, L.X. Zheng, H. Wu, and S.Y. Tong, Anisotropic step-flow growth and island growth of $\mathrm{GaN}(0001)$ by molecular beam epitaxy, Phys. Rev. Lett. 82(13), 2749-2752 (1999).

[24]J.E. Northrup and J. Neugebauer, Indium induced changes in $\mathrm{GaN}(0001)$ surface morphology, Phys. Rev. B 60(12), R8473-R8476 (1999).

[25]P. Waltereit, O. Brandt, A. Trampert, H.T. Grahn, J. Menniger, M. Ramsteiner, M. Reiche, and K.H. Ploog, Nitride semiconductors free of electrostatic fields for efficient white light-emitting diodes, Nature 406, 865-868 (2000).
[26]S. Marcinkevičius, K.M. Kelchner, L.Y. Kuritzky, S. Nakamura, S.P. DenBaars, and J.S. Speck, Highly polarized photoluminescence and its dynamics in $(20 \overline{2} \overline{1}) \mathrm{InGaN} / \mathrm{GaN}$ quantum well, Appl. Phys. Lett. 103, 111107 (2013).

[27]O. Marquardt, T. Hickel, J. Neugebauer, and C.G. Van de Walle, Polarization effects due to thickness fluctuations in nonpolar InGaN/GaN quantum wells, Appl. Phys. Lett. 103, 073115 (2013).

[28]R. Ivanov, S. Marcinkevičius, Y. Zhao, D.L. Becerra, S. Nakamura, S.P. DenBaars, and J.S. Speck, Impact of carrier localization on radiative recombination times in semipolar $(20 \overline{2} 1)$ plane InGaN/ GaN quantum wells, Appl. Phys. Lett. 107, 211109 (2015).

[29]S. Schulz, D.P. Tanner, E.P. O'Reilly, M.A. Caro, T.L. Martin, P.A.J. Bagot, M.P. Moody, F. Tang, J.T. Griffiths, F. Oehler, M.J. Kappers, R.A. Oliver, C.J. Humphreys, D. Sutherland, M.J. Davies, and P. Dawson, Structural, electronic, and optical properties of $m$-plane InGaN/GaN quantum wells: Insights from experiment and atomistic theory, Phys. Rev. B 92, 235419 (2015).

[30]H. Masui, H. Yamada, K. Iso, S. Nakamura, and S.P. DenBaars, Optical polarization characteristics of $m$-oriented InGaN/GaN light-emitting diodes with various indium compositions in single-quantum-well structure, J. Phys. D 41, 225104 (2008).

[31]W. Shan, T.J. Schmidt, X.H. Yang, S.J. Hwang, J.J. Song, and B. Goldenberg, Temperature dependence of interband transitions in $\mathrm{GaN}$ grown by metalorganic chemical vapor deposition, Appl. Phys. Lett. 66, 985 (1994).

[32]N. Rotenberg and L. Kuipers, Mapping nanoscale light fields, Nat. Photonics 8, 919 (2014).

[33]Y.J. Sun, O. Brandt, M. Ramsteiner, H.T. Grahn, and K.H. Ploog, Polarization anisotropy of the photoluminescence of $M$-plane (In, Ga)N/ GaN multiple quantum wells, Appl. Phys. Lett. 82(22), 3850-3852 (2003).

[34]C. Mounir, U.T. Schwarz, I.L. Koslow, M. Kneissl, T. Wernicke, T. Schimpke, and M. Strassburg, Impact of inhomogeneous broadening on optical 
polarization of high-inclination semipolar and nonpolar $\operatorname{In}_{x} \mathrm{Ga}_{1-x} \mathrm{~N} / \mathrm{GaN}$ quantum wells, Phys. Rev. B 93, 235314 (2016).

[35]S. Marcinkevičius, R. Ivanov, Y. Zhao, S. Nakamura, S.P. DenBaars, and J.S. Speck, Highly polarized photoluminescence and its dynamics in $(20 \overline{2} \overline{1})$ InGaN/GaN quantum well, Appl. Phys. Lett. 104, 111113 (2014).

[36] L. Schade, U.T. Schwarz, T. Wernicke, M. Weyers, and M. Kneissl, Impact of band structure and transition matrix elements on polarization properties of the photoluminescence of semipolar and nonpolar InGaN quantum wells, Phys. Status Solidi B 248(3), 638-646 (2011).

[37]K. Alberi, B. Fluegel, H. Moutinho, R.G. Dhere, J.V. Li, and A. Mascarenhas, Measuring longrange carrier diffusion across multiple grains in polycrystalline semiconductors by photoluminescence imaging, Nat. Commun. 4, 2699 (2013).
[38]R. Aleksiejūnas, M. Sūdžius, V. Gudelis, T. Malinauskas, K. Jarašiūnas, Q. Fareed, R. Gaska, M.S. Shur, J. Zhang, J. Yang, E. Kuokštis, and M.A. Khan, Carrier transport and recombination in InGaN/GaN heterostructures, studied by optical four-wave mixing technique, Phys. Status Solidi C 0(7), 2686-2690 (2003).

[39] M. Mensi, R. Ivanov, T.K. Uždavinys, K.M. Kelchner, S. Nakamura, S.P. DenBaars, J.S. Speck, and S. Marcinkevičius, Direct measurement of nanoscale lateral carrier diffusion: toward scanning diffusion microscopy, ACS Photonics 5(2), 528-534 (2018).

[40]S.-H. Park, D. Ahn, and S.L. Chuang, Electronic and optical properties of $a$ - and $m$-plane wurtzite InGaN-GaN quantum wells, IEEE J. Quantum Electron. 43(12), 1175-1182 (2007).

\title{
DAUGIAKANALE் SKENUOJANTI ARTIMO LAUKO FOTOLIUMINESCENCIJOS SPEKTROSKOPIJA IR JOS TAIKYMAS InGaN EPITAKSINIŲ SLUOKSNIŲ IR KVANTINIŲ DUOBIŲ TYRIMUI
}

\author{
S. Marcinkevičius, T.K. Uždavinys, R. Ivanov, M. Mensi \\ KTH Karališkasis technologijos institutas, Kista, Švedija
}

\begin{abstract}
Santrauka
Aptariami pastarųjų metų pasiekimai plètojant daugiakanalę skenuojančios artimo lauko optinès mikroskopijos (SAOM) metodiką. Naudojant ši eksperimentini metodą tuo pat metu galima skenuoti dvimati fotoliuminescencijos spektrų ir jų dinamikos pasiskirstymą ir bandinio paviršiaus morfologiją. Skenuojančios daugiakanalès mikroskopijos galimybės iliustruojamos polinių InGaN epitaksinių sluoksnių ir nepolinių In-
\end{abstract}

GaN / GaN kvantinių duobiu tyrimais. SAOM eksperimentai sudare galimybes ištirti dvimates energijos juostų potencialo variacijas, jų fizikinę prigimtị ir koreliaciją su bandinio paviršiaus morfologija. Taip pat buvo pademonstruotas spindulinès ir nespindulinès rekombinacijos laikų erdvinis netolygumas. Galiausiai parodyta, kaip matuojant keliais SAOM režimais tuo pat metu galima ịvertinti ambipolinę krūvininkų difuziją ir jos anizotropiją. 